\title{
AIAA 2001-0786 \\ Laser Soot-Mie Scattering in a Reacting Vortex Ring
}

Shin-Juh Chen and Werner J.A. Dahm

Laboratory for Turbulence \& Combustion (LTC)

Department of Aerospace Engineering

The University of Michigan

Ann Arbor, MI 48109-2140

Michael Millard and Randall L. Vander Wal

NASA-Glenn Research Center

National Center for Microgravity Research

M.S. 110-3

21000 Brookpark Road

Cleveland, $\mathrm{OH} 44153$

\section{9th AIAA Aerospace Sciences Meeting \& Exhibit 8-11 January 2001 / Reno, NV}




\title{
Laser Soot-Mie Scattering in a Reacting Vortex Ring
}

\author{
Shin-Juh Chen ${ }^{1}$ and Werner J.A. Dahm² \\ Laboratory for Turbulence \& Combustion (LTC) \\ Department of Aerospace Engineering \\ The University of Michigan, Ann Arbor, MI 48109-2140
}

\author{
Michael Millard ${ }^{3}$ and Randall L. Vander Wal ${ }^{4}$ \\ NASA-Glenn Research Center \\ National Center for Microgravity Research \\ 21000 Brookpark Road \\ Cleveland, OH 44153
}

\begin{abstract}
The technique of Laser Soot-Mie Scattering (LSMS) is utilized to study the effect of fuel volume and ring circulation on the formation and evolution of soot in reacting vortex rings. Propane reacting in air at atmospheric conditions under microgravity is considered. Diffusion flame-vortex ring interaction contains the fundamental elements of flow, mixing, combustion, and soot processes found in practical turbulent reacting flows. Flame-vortex interaction allows these fundamental processes to be studied under more controllable conditions than direct investigation of these elements in practical flames. Soot concentration was found to be higher in regions of lower strain and along the periphery of the reacting vortex rings. No soot was found inside the reacting vortex ring, however soot was enclosed inside the flame zone. Future quantification of these soot concentrations will allow researchers to test their models of soot against these experimental results. In addition, flame-vortex interaction provides an attractive configuration for numerical simulations due to its simplicity than a full calculation of turbulent reacting flows, and yet containing the fundamental processes found in practical reacting flows.
\end{abstract}

\section{INTRODUCTION}

The presence of soot in a reacting flow can contribute to radiative heat loss in flames $[16,30]$ which can affect the combustion processes, and flame structure and dynamics. Due et al. [11] examined experimentally and numerically the effect of flame structure on soot-inception and that soot-inception is suppressed as flame shifts toward the fuel side. The effects of gaseous additives on soot formation have been studied by Du et al. [12]. Soot is an unwanted source of pollution and needs to be controlled properly for the various industrial applications of turbulent reacting flows. With increased regulatory pressures there is urgent need to find solutions for the reduction of soot, especially in diesel engines. However, there is still no full understanding of the fundamental processes of soot nucleation, growth, and

1. Research Fellow; AIAA Student Member.

2. Professor; AIAA Senior Member; Corresponding author.

3. Research Scientist; currently at Kodak, Rochester, NY.

4. Staff Scientist.

Copyright $(\mathcal{O}$ by Shin-Juh Chen oxidation. Soot has been found to be carrier of pollutants such as Polyaromatic Hydrocarbons (PAH) [23], and a strong correlation exists between soot and $\mathrm{CO}$ which are results of incomplete combustion [31]. CO is the main product of the oxidation of soot particles. Polynuclear Aromatic Compounds (PAC) are often associated with soot emissions and can be a health hazard. These compounds are found in the burning of biomass [20].

Modeling soot processes can be done in several ways [19]. Empirical model can be used to build correlations that will be useful in extrapolating the results to other conditions that are close to those of the experimental results. Semi-empirical model solves rate equations for soot and use some experimental data. These rate equations include the processes of soot nucleation, soot particle growth, and soot oxidation. Detailed model attempts to predict the whole soot formation process, i.e. from fuel to PAH and to soot, and includes the descriptions of the soot physics and soot chemistry $[22,22,28,36]$. All models require some adjustments to several parameters, and this makes it difficult to identify any single model that is better than others [19]. 
Soot particles can be visualized in several ways. Understanding the physical properties of soot are also important in modeling its optical properties [13] which are necessary for some of the soot diagnostic tools. Laser Soot-Mie Scattering (LSMS) results provide qualitative maps of the soot field and its time evolution [26]. Relative concentration of soot can be visualized using LaserInduced Fluorescence (LIF) [33]. Laser-Induced Incandescence (LII) can provide both qualitative and quantitative soot concentration with some calibration needed [9,29,32-33]. Another quantitative technique is Thermocouple Particle Densitometry (TPD) [25]. Soot structures can be studied using techniques of Transmission Electron Microscope (TEM) [33] and Laser Microprobe Mass Spectrometry (LMMS) [10].

Flame-vortex interaction provides an ideal candidate for studying soot processes due to its simplicity in flowfield and modeling yet containing the complexities found in turbulent reacting flows. The interaction between fluid dynamics and combustion that occurs in turbulent reacting flows can be investigated in a canonical configuration of a flame-vortex interaction which contains the fundamental elements of flow, mixing, combustion, and soot processes found in turbulent reacting flows. Flame-vortex interaction provides a controlled environment in which these fundamental elements can be studied with much more ease than a direct investigation of turbulent reacting flows. Such simplified flowfield allows the complex processes to be examined closely and yet preserving the physical processes present in practical reacting flows. Furthermore, experimental results from the study of flame-vortex interactions are useful for the validation of numerical simulations and more importantly to deepen our understanding of the fundamental processes present in reacting flows.

The configuration chosen in this study is similar to that used in the analyses of Karagozian \& Manda [17] and Manda \& Karagozian [24] of their 2-D vortex pair in which both fuel and entrained oxidizer are present. Reacting vortex rings are generated by issuing fuel through an axisymmetric nozzle which has a diffusion flame initially established at the nozzle exit. As the vortex ring emerges from the nozzle exit, it wraps the diffusion flame to generate a burning vortex ring. The

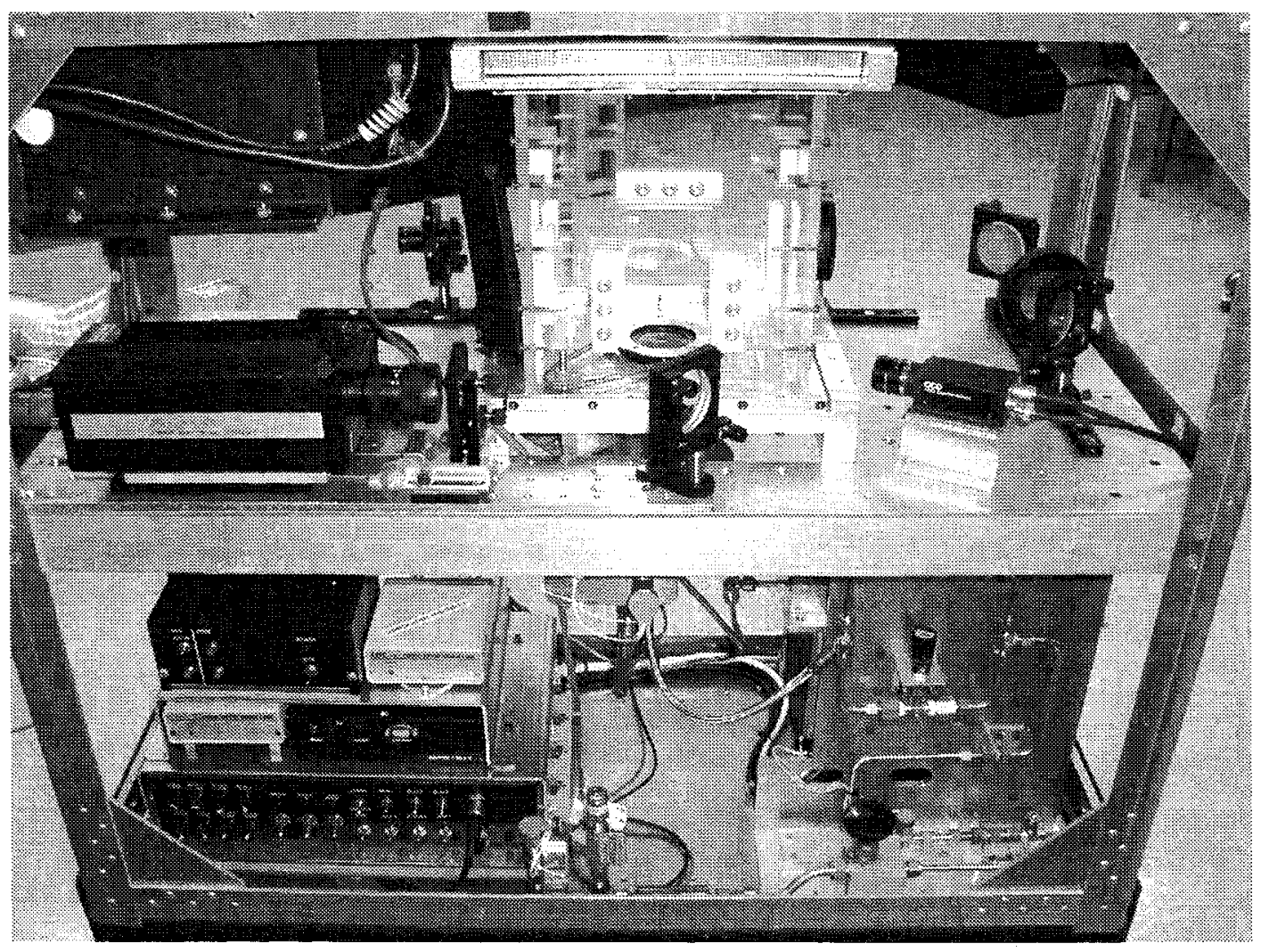

Figure 1. Experiment drop package showing laser beam forming optics, ICCD camera, B/W CCD camera, test section, power supply for spark generator, and nozzle/plenum assembly on top shelf. The vortex generator system, power distributor, batteries, and video transmitters reside on the bottom shelf. 


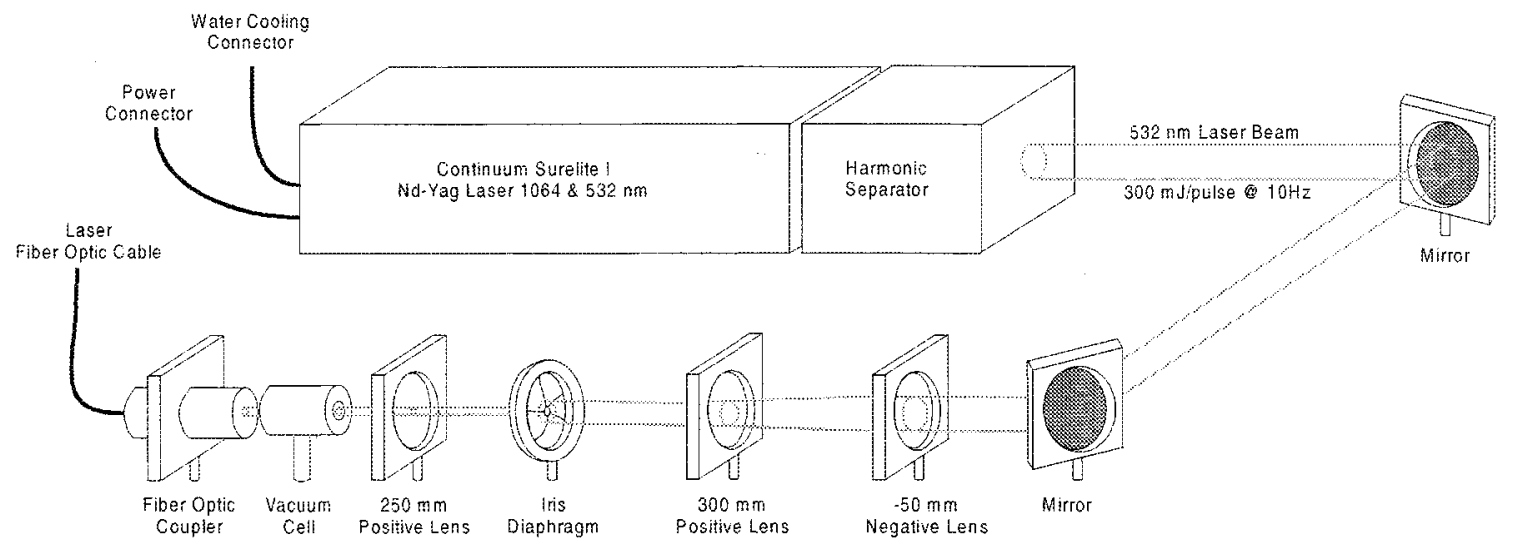

Figure 2. Schematic of the Nd-Yag laser system sitting on top of the NASA-Glenn 2.2 sec drop tower facility. Laser beam is focused onto a fiber optic cable that is connected to the drop package.

burning ring propagates downstream up to a point due to effects of dilatation while consuming the fuel enclosed in the vortex ring. The current configuration has been experimentally studied by Chen [1], Chen \& Dahm [25] and Chen et al. [6-8] under microgravity conditions. Park \& Shin [27] and You et al. [35] have also studied this configuration under normal gravity conditions.

The study of soot in the chosen configuration provides means to address the many effects of fluid dynamics and chemistry on the soot processes. Furthermore, the experimental results from this simple configuration can also provide as tests for the numerical simulations of soot processes. The formation and evolution of soot generated by the reacting vortex rings are imaged using the technique of LSMS for various fuel volumes and ring circulations. Propane reacting in air at atmospheric conditions is used in all experiments. This paper examines the hydrodynamic effect on the evolution and formation of soot in reacting vortex rings under microgravity conditions.

\section{EXPERIMENT METHODS}

\subsection{Experiment Drop Rig}

All experiments were conducted at the NASA-Glenn 2.2 seconds drop tower facility which can provide g-level of about $10^{-4}$. The facility consists of a 8 -story building with an airbag in the basement to aid in the deceleration process. Experiment drop package is loaded on the 5th floor unto a drag shield to reduce air drag during the 24$\mathrm{m}$ decent. The whole package is raised to the ceiling of the 8th floor and awaits instructions for the drop sequence from the operator. The existing drop rig of
Chen [1], Chen \& Dahm [2-5] and Chen et al. [6-8] is modified to implement the setup of LSMS to investigate the soot field generated by reacting vortex rings. Refer to Chen [1] for details of the experimental drop rig used in the study of reacting vortex rings.

Figure 1 shows the experiment drop package with the LSMS optical setup, test section, nozzle/plenum assembly, CCD camera, and power supply for the spark generator on the top shelf. The bottom shelf houses the vortex generator system which consists of flowmetering valves, fast-acting solenoid valve, shut-off valve, and tubing. A vacuum system, power distributor, video transmitters, and an on-board computer (DDCAS, Dropable Data Acquisition System) are also located on the bottom shelf.

A microgravity experiment generally proceeds by first purging the vortex generator system and nozzle/plenum assembly with fuel. One section of the tubing is filled with pressurized fuel which when released for a very short time $(5-100 \mathrm{msec})$ through the action of a fast-acting solenoid valve generates a vortex ring. By varying the fuel pressure and duration of open solenoid valve, different ring circulations and fuel volumes can be achieved. The combustion chamber, which is made of clear Lucite $(20 \mathrm{~cm} \times 25 \mathrm{~cm} \times 25 \mathrm{~cm})$ and open to the atmosphere, is flushed with clean air to remove dust particles and residual fuel. Since the iris diaphragm that separates the fuel and air interfaces does not completely close and with a time lag of 10-15 minutes after the initial purging, re-purging of the nozzle/plenum assembly with fuel is necessary just before the initiation of the drop sequence to achieve successful ignitions.

Prior to the drop, the motor-driven iris diaphragm opens 


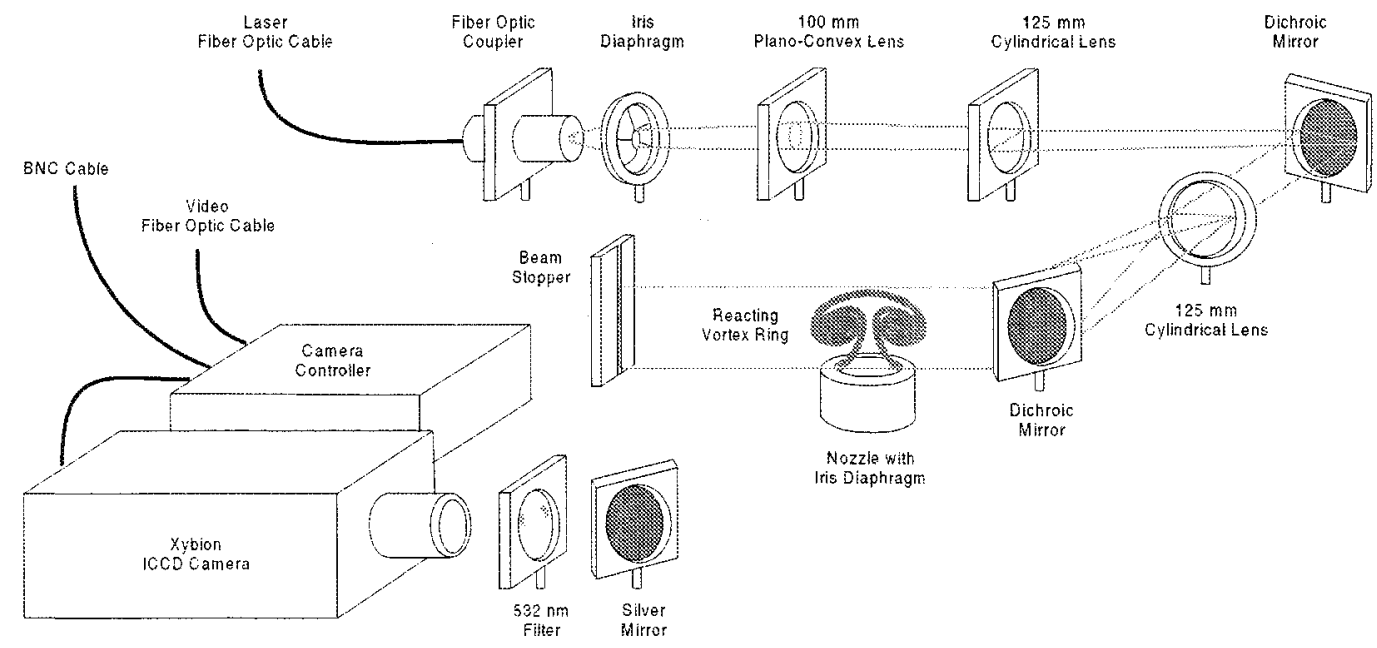

Figure 3. Schematic of the laser beam forming optics residing on the top shelf of the experiment drop package. Laser soot-mie scattering signals are recorded using an intensified CCD camera.

and exposes the fuel to the air. Inter-diffusion (lasting $950 \mathrm{msec}$ ) between the fuel and oxidizer generates a diffusion layer which is pulled toward the ignitor inside the nozzle/plenum assembly by opening a vacuum tank (75 cc, initially at 25 " of $\mathrm{Hg}$ ) for a period of $400 \mathrm{msec}$. Ignition of the diffusion layer is achieved through a spark ignitor. The package is released from the top of the tower. After 10-15 msec of drop time where the diffusion flame has sufficiently stabilized and flattened, the fast-acting solenoid valve opens to release pressurized fuel into the nozzle/plenum assembly to generate a vortex ring. As the vortex ring emerges from the nozzle exit $(D=2 \mathrm{~cm}$ dia.), it wraps the already formed diffusion flame to produce a reacting vortex ring. The black and white CCD camera (Sony, XC-75, $640 \times 480$ pixels) records the flame luminosity over a region of $6 \mathrm{~cm}$ $\times 8 \mathrm{~cm}$ (height and width).

Propane-air combustion is studied in all experiments presented in this paper. Ring circulation and fuel volume are varied to study their effect on the evolution and formation of soot in reacting vortex rings under microgravity conditions.

\subsection{Laser Soot-Mie Scattering System}

The LSMS system is composed of two optical setups with one on the drop rig and the other on the 8th floor of the drop tower. The laser system (Fig. 2) is composed of a Nd-Yag laser (Continuum Surelite 1, $6 \mathrm{~ns}$ pulse at $10 \mathrm{~Hz}$, and $300 \mathrm{~mJ} /$ pulse) that sits at the top of the drop tower and optics to focus the beam unto a fiber optic cable. A harmonic separator extracts the $532 \mathrm{~nm}$ from the $1064 \mathrm{~nm}$. The $532 \mathrm{~nm}$ beam passes through two turning mirrors, and a negative lens of $-50 \mathrm{~mm}$ and a $300 \mathrm{~mm}$ lens are used to collimate the laser beam. The collimated beam then passes through an iris diaphragm with a central opening of about $10 \mathrm{~mm}$ to capture just the central portion of the beam. A $250 \mathrm{~mm}$ lens is used to focus the laser beam an inch away from the end of the fiber optic cable. The focus of the beam lies inside a glass vacuum cell that prevents laser breakdown of the air. A 35-m long section of a high- $\mathrm{OH}$ content, 1000 $\mu \mathrm{m}$ core diameter with $30 \mu \mathrm{m}$ of cladding thickness, optical fiber delivers the laser pulses (about 8-10 mJ/ pulse) from the top of the drop tower to the drop rig. A high power SMA-905 input connector couples the pulsed laser light to the optical fiber.

Soot-mie scattering signals were detected using an intensified CCD camera (Xybion, ISG-250 ICCD, $660 \times$ 480 pixels) with a UV lens (f $50 \mathrm{~mm}, 1: 3.5$ ) through a $532 \mathrm{~nm}$ filter and imaging a region of $4.3 \mathrm{~cm} \times 5.9 \mathrm{~cm}$ (height and width). Power to the intensified CCD camera was provided through a custom built module powered by $28 \mathrm{~V}$ batteries. This module coupled the video signal and timing signals out of the ICCD camera and gate pulse into the camera intensifier. Video signals from both cameras are sent to on-board fiber-optic video transmitters which are relayed to the top of the drop tower for video recordings on BETA and s-VHS tapes via fiber-optic cables. In order to synchronize the ICCD camera with the laser pulses, a 35-m long BNC (RG58) cable linked the camera system to the delay generators of the laser system.

Figure 3 shows a schematic of the optical layout of the LSMS system on the drop rig. Inside the drop rig, the end of the fiber optic cable transmitting the laser pulses is secured unto an output fiber optic coupler. The beam is spatially filtered by passing through a $3 \mathrm{~mm}$ opening of an iris diaphragm. A plano-convex lens $(100 \mathrm{~mm})$ collimates the beam, and a cylindrical lens $(125 \mathrm{~mm})$ collapses the collimated beam horizontally. A dichroic mirror (coated $532 \mathrm{~mm}$ ) turns the beam to a 90 degree 
position which then passes through another cylindrical lens $(125 \mathrm{~mm})$ which shrinks the beam horizontally to form the vertical beam spot of interest. A second dichroic mirror positions the formed laser beam precisely along the nozzle centerline. Just above the nozzle exit, the laser beam, with thickness of about $1 \mathrm{~mm}$, is $6 \mathrm{~cm}$ in height with little beam divergence over a width of $6 \mathrm{~cm}$. A beam dump is used to eliminate laser light scattering after the formed laser beam passes through the test section. The generated soot-mie scattering signals pass through the $532 \mathrm{~nm}$ filter, and are recorded by the intensified ICCD camera with field of view positioned 90 degrees to the laser beam through the aid of a silver mirror due to space constraint.

\section{RESULTS AND DISCUSSIONS}

Propane-air combustion cases were examined under microgravity conditions to investigate the effects of fuel volume and ring circulation on the soot field. The conditions for two propane-air cases are $\Gamma=80 \mathrm{~cm}^{2} / \mathrm{s}$ with $V_{F}=12 \mathrm{cc}$ for case $\mathrm{A}$, and $\Gamma=190 \mathrm{~cm}^{2} / \mathrm{s}$ with $V_{F}=22$ cc for case $B$.

For each case two set of images are shown which resulted from flame luminosity and LSMS imaging of reacting vortex rings. Side view of flame luminosity results, recorded by a $\mathrm{B} / \mathrm{W} \mathrm{CCD}$ camera at 30 frames per second, are shown in Figs. $4 a$ and 5a. Vertical 2-D cut along the center of the reacting vortex ring, recorded by the ICCD camera at 10 frames per second, are shown in Figs. $4 b$ and $5 b$. Images from the two visualization techniques are time-matched as closely as possible for the purposes of comparison. All images are shown in inverse grayscale in order to accentuate the bright regions seen in the video images. The flame luminosity results are useful in identifying the flame structure and ring dynamics of the burning vortex rings. Due to the limitation (running at $10 \mathrm{~Hz}$ ) of LSMS system, rings with high ring circulations and low fuel volumes were avoided since only a few frames could be recorded on the ICCD camera. In the flame luminosity results, some white regions are present along the bottom side of the boxed frame. These are due to missing pixels. From the LSMS imaging most of the dark regions observed in the flame luminosity results can now be attributed to the presence of soot. The laser power and the ICCD camera gain were set to same values for both cases. This allows a visual comparison of relative soot concentrations between the cases to be conducted.

In the early stage of interaction of case A, dark regions are seen on the forward stagnation region of the reacting vortex ring (1st frame of Fig. 4a). LSMS images indicate that high concentration of soot appears along the periphery of the reacting vortex ring with less concentration along the forward stagnation point. Due to high straining along the forward stagnation point, soot production is diminished. Strain has the effect of reducing the time available for the processes of soot nucleation and soot particle growth to proceed [18]. In the latter stage of interaction (2nd frame of Fig. 4a), the upper section of the vortex ring is covered with a very dark region. LSMS results (Fig. 4b) reveal that soot are only located along the ring periphery but inside the flame zone. The ring is no longer moving downstream due to the effect of dilatation. From the soot field of Fig. $4 b$ there is clear indication that there is no high strain field along the forward stagnation point since the relative soot concentration along this region is the same throughout.

With an increase in ring circulation (more than double) and increase in fuel volume (less than double), flame luminosity results of Fig. Sa shows a larger burning vortex ring since there is more fuel released from the nozzle. Moreover, the increase in ring circulation has obviously caused the burning vortex ring to propagate further downstream than the previous case. The fuel volume is still below the limit of overfilled vortex rings ( $L / D$ between 3.6 and 4.4, Gharib et al. [14]) since the $L D$ ratio in this case is about 3.5 , where $L$ and $D$ denotes the length of column of injected fluid and the nozzle diameter, respectively. The soot field shown in Fig. $5 \mathrm{~b}$ are very different than those of Fig. $4 \mathrm{~b}$. No soot concentration is seen along the forward stagnation point for the sequence of images shown. Due the increase in ring circulation the strain field along the forward stagnation is much higher than the previous case and remains so for a longer period of time because of a larger fuel volume. In these regions of high strain, the flame temperature has decreased to the level below that needed for soot formation but not enough to cause the flame to be extinguished [15] as evidenced in the flame luminosity results of Fig. 5a. Throughout the interaction soot concentration remains along the periphery of the burning vortex ring and inside the flame zone. No soot was observed inside the vortex ring. Soot appears to be present in regions of long residence time that is necessary for the processes of soot nucleation and growth to proceed.

\section{CONCLUSIONS}

The soot field in reacting vortex rings were imaged by the method of Laser Soot-Mie Scattering (LSMS) under microgravity conditions. LSMS revealed new insights of the soot field inside reacting vortex rings which could not have been possible from inspection of the flame luminosity results. Soot was not present in regions of high strain and was found to be along the periphery of the reacting vortex ring but inside the flame zone.

Future quantification of soot concentrations, such as Laser-Induced Incandescence technique, in reacting vortex rings should be of great interest to the modeling of soot formation and oxidation. The experimental results can serve as a tests for the soot models developed by researchers. The canonical configuration of flamevortex interaction is ideal for simulating the complex physical processes present in practical reacting flows yet keeping the flowfield and computational domain simple. Computations using this canonical configuration are far less restrictive in time and resources than a full calculation of a turbulent reacting flows. 

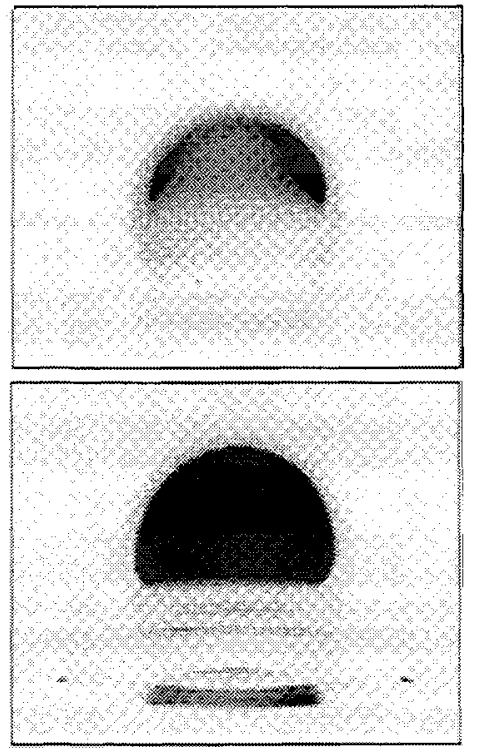

(a)
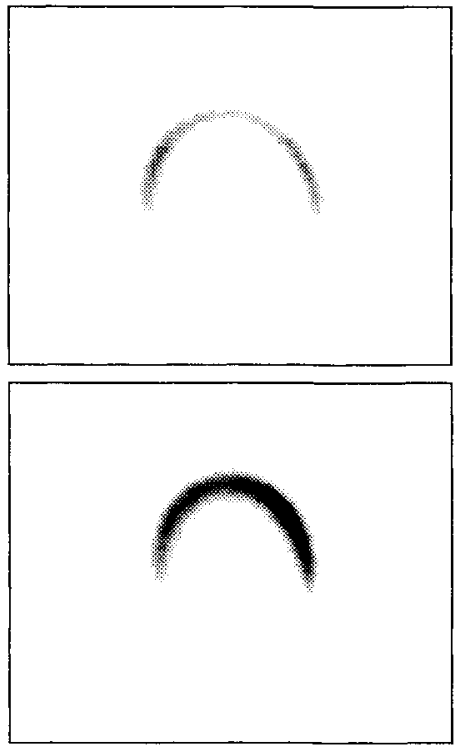

(b)

Figure 4. Case A showing results from (a) flame luminosity and (b) LSMS for propane issuing into an air environment at atmospheric condition under microgravity. The fuel volume is $12 \mathrm{cc}$, and ring circulation is $80 \mathrm{~cm}^{2} / \mathrm{sec}$.

\section{Acknowledgements}

This research is been sponsored by the NASA Microgravity Combustion Science Program under Contract No. NASA-G-NAG3-1639. Part of the funding was awarded through NASA cooperative agreement NCA3544 with The National Center for Microgravity Research on Fluids and Combustion

\section{References}

[1] Chen, S.-J. (2000) Experimental and numerical study of fluid dynamics-combustion coupling in a diffusion flame-vortex ring interaction. Ph.D. Dissertation. University of Michigan, Ann Arbor, Michigan.

[2] Chen, S.-J., and Dahm, W.J.A. (1997) Vortex ring/diffusion flame interactions in microgravity conditions. Fourth International Microgravity Combustion Workshop, NASA CP-10191, 191-196.

[3] Chen, S.-J., and Dahm, W.J.A. (1998) Diffusion flame structure of a laminar vortex ring under micro- gravity conditions. Proc. Combust. Inst. 27:2579-2586.

[4] Chen, S.-J., and Dahm, W.J.A. (1999) Experiments on diffusion flame structure of a laminar vortex ring. First Joint Meeting of the U.S. Sections of the Combustion Institute, The Combustion Institute, Pittsburgh, PA, 461-464.

[5] Chen, S.-J., and Dahm, W.J.A. (1999) The interaction of a vortex ring with a diffusion flame under microgravity conditions. Fifth International Microgravity Combustion Workshop, NASA CP-208917, 271274.

[6] Chen, S.-J., Dahm, W.J.A., and Tryggvason, G. (2000) Coupling between fluid dynamics and combustion in a laminar vortex ring. AIAA Paper No. 20000433, AIAA, Washington, DC.

[7] Chen, S.-J., Dahm, W.J.A., and Tryggvason, G. (2000) Results from numerical simulations of the diffusion flame-vortex ring interaction. AIAA Paper No. 2000-2468, AIAA, Washington, DC.

[8] Chen, S.-J., Dahm, W.J.A., and Tryggvason, G. (2000) Effects of heat release in a reacting vortex ring. 

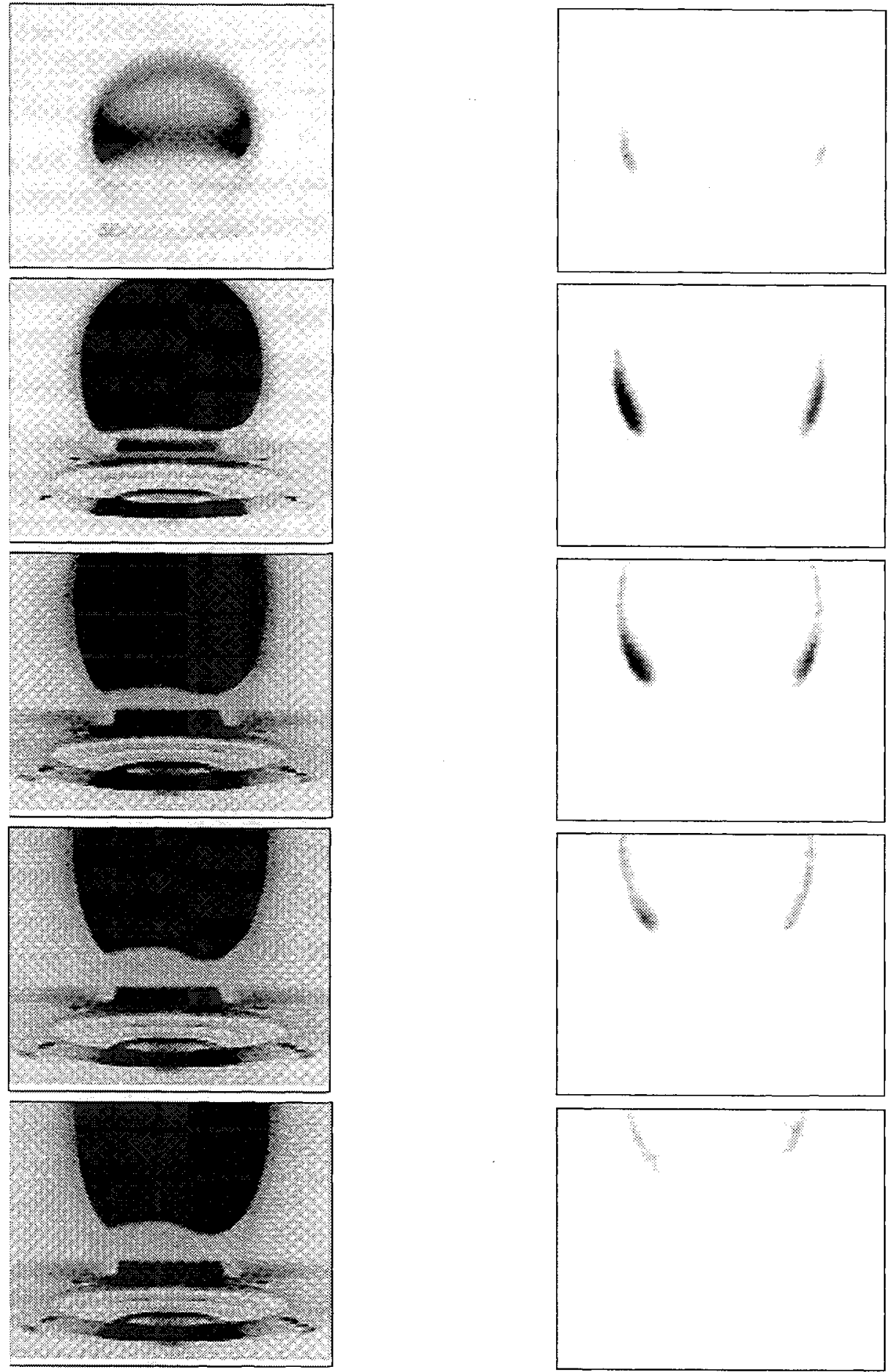

(a)

(b)

Figure 5. Case $\mathrm{C}$ showing results from $(a)$ flame luminosity and $(b)$ LSMS for propane issuing into an air environment at atmospheric condition under microgravity. The fuel volume is $22 \mathrm{cc}$, and ring circulation is $190 \mathrm{~cm}^{2} / \mathrm{sec}$. 
Proc. Combust. Inst. 28. To Appear.

[9] Choi, M.Y. and Jensen, K.A. (1998) Calibration and correction of laser-induced incandescence for soot volume fraction measurements. Comb. Flame 112:485. 491.

[10] Dobbins, R.A., Fletcher, R.A., and Chang, H.-C. (1998) The evolution of soot precursor particles in a diffusion flame. Comb. Flame 115:285-298.

[11] Du, J., and Axelbaum, R.L. (1995) The effect of flame structure on soot-particle inception in diffusion flames. Comb. Flame 100:367-375.

[12] Du, D.X., Axelbaum, R.L, and Law, C.K. (1995) Soot formation in strained diffusion flames with gaseous additives. Comb. Flame 102:11-20.

[13] Faeth, G.M. and Köylü, Ü.Ö. (1995) Soot morphology and optical properties in nonpremixed turbulent flame environments. Combust. Sci. and Tech. 108:207229.

[14] Gharib, M., Rambod, E., and Shariff, K. (1998) A universal time scale of vortex ring formation. J. Fluids Mech. 360:121-140.

[15] Glassman, I. and Yaccarino, P. (1981) Proc. Combust. Inst. 18:1175-1183.

[16] Hamadi, M.B., Vervisch, P., and Copalle, A. (1987) Radiation properties of soot from premixed flat flame. Comb. Flame 68:57-67.

[17] Karagozian, A.R., and Manda, B.V.S. (1986) Flame structure and fuel consumption in the field of a vortex pair. Combust. Sci. Tech. 49:185-200.

[18] Kennedy, I.M. (1985) Flow field effects on nucleation in a reacting mixing layer. Phys. Fluids 28:3515-3524.

[19] Kennedy, I.M. (1997) Models of soot formation and oxidation. Prog. Energy Combust. Sci. 23:95:132.

[20] Kozinski, J.A., and Saade, R. (1997) Effect of biomass burning on the formation of soot particles and heavy hydrocarbons. An experimental study. Fuel 77 (4):225-237.

[21] Krestinin, A.V. (2000) Detailed modeling of soot formation in hydrocarbon pyrolysis. Comb. Flame 121:513-524.

[22] Kronenburg, A., Bilger, R.W., and Kent, J.H. (2000) Modeling soot formation in turbulent methaneair jet diffusion flames. Comb. Flame 121:24-40.

[23] Lahaye and Prado (1981) Morphology and internal structure of soot and carbon blacks. Siegla, D.C. and Smith, G.W. (ed.). Particulate Carbon, Plenum Press, NY. 33-55.
[24] Manda, B.V.S., and Karagozian, A.R. (1988) Effects of heat release on diffusion flame-vortex pair interactions. Combust. Sci. Tech. 61:101-119.

[25] Mcenally C.S., Köylü, Ü.Ö., and Pferfferle, L.S., and Rosner, D.E. (1997) Soot volume fraction and temperature measurements in laminar non premixed flames using thermocouples. Comb. Flame 109:701-720.

[26] Miake-Lye R.C. and Toner, S.J. (1987) Laser soot-scattering imaging of a large buoyant diffusion flame. Comb. Flame 67:9-26.

[27] Park, J., and Shin, H.D. (1997) Experimental investigation of the developing process of an unsteady diffusion flame. Comb. Flame 110:67-77.

[28] Said, R., Garo, A., and Borghi, R. (1997) Soot formation modeling for turbulent flames. Comb. Flame 108:71-86.

[29] Shaddix, C.R., and Smyth, K.C. (1996) Laserinduced incandescence measurements of soot production in steady and flickering methane, propane, and ethylene diffusion flames. Comb. Flame 107:418-452.

[30] Sivathanu, Y.R., and Gore, J.P. (1993) Total radiative heat loss in jet flames from single point radiative flux measurements. Comb. Flame 94:265-270.

[31] Tewarson, A. (1988) Generation of heat and chemical compounds in fires. In SPFE Handbook on Fire Protection Engineering, National Fire Protection Association, Quincy, MA. 1-179.

[32] Vander Wal, R.L. (1997) Characterization and demonstration of laser-induced incandescence in both normal and low-gravity. NASA Contractor Report 202347.

[33] Vander Wal, R.L. (1998) Soot precursor carbonization: visualization using LIF and LII and comparison using bright and dark field TEM. Comb. Flame 112:607-616.

[34] Vander Wal, R.L., Choi, M.Y., and Lee, K.O. (1995) The effects of rapid heating soot: implications when using laser-induced incandescence for soot diagnostics. Comb. Flame 102:200-204.

[35] You, Y.H., Lee, D.K., and Shin, H.D. (1998) Visual investigation of a vortex ring interacting with a nonpremixed flame. Combust. Sci. Tech. 139:365-383.

[36] Zimberg, M.J., Frankel, S.H., Gore, J.P., and Sivathanu, Y.R. (1997) A study of coupled turbulent mixing, soot chemistry, and radiation effects using the linear eddy model. Comb. Flame 113:454-469. 